\title{
Standard selection modes in dynamic, complex industries : creating hybrids between market selection and negotiated selection of standards
}

Citation for published version (APA):

Vercoulen, F., \& van Wegberg, M. J. (1998). Standard selection modes in dynamic, complex industries : creating hybrids between market selection and negotiated selection of standards. NIBOR, Netherlands Institute of Business Organization and Strategy Research. NIBOR Research Memorandum No. 06 https://doi.org/10.26481/umanib.1998006

Document status and date:

Published: 01/01/1998

DOI:

10.26481/umanib.1998006

Document Version:

Publisher's PDF, also known as Version of record

Please check the document version of this publication:

- A submitted manuscript is the version of the article upon submission and before peer-review. There can be important differences between the submitted version and the official published version of record.

People interested in the research are advised to contact the author for the final version of the publication, or visit the DOI to the publisher's website.

- The final author version and the galley proof are versions of the publication after peer review.

- The final published version features the final layout of the paper including the volume, issue and page numbers.

Link to publication

\footnotetext{
General rights rights.

- You may freely distribute the URL identifying the publication in the public portal. please follow below link for the End User Agreement:

www.umlib.nl/taverne-license

Take down policy

If you believe that this document breaches copyright please contact us at:

repository@maastrichtuniversity.nl

providing details and we will investigate your claim.
}

Copyright and moral rights for the publications made accessible in the public portal are retained by the authors and/or other copyright owners and it is a condition of accessing publications that users recognise and abide by the legal requirements associated with these

- Users may download and print one copy of any publication from the public portal for the purpose of private study or research.

- You may not further distribute the material or use it for any profit-making activity or commercial gain

If the publication is distributed under the terms of Article 25fa of the Dutch Copyright Act, indicated by the "Taverne" license above, 


\section{Standard Selection Modes in Dynamic, Complex Industries:}

\section{Creating Hybrids between Market Selection and Negotiated Selection of Standards ${ }^{1}$}

Frank Vercoulen ${ }^{2}$ and Marc van Wegberg ${ }^{3}$

NIBOR / RM / 1998 / 06

October, 1998

Abstract. Several sectors within Information and Communication Technology demonstrate a shift from purely market-based selection of standards or purely negotiated selection of standards to hybrid selection processes, where both market competition and negotiation play a role. Negotiated standard setting processes (such as those organised by the ITU) assure interoperability of technical components and services. Private firms, however, increasingly tend to undercut these collective actions. Their innovations jump-start new developments, but also create incompatibilities, lock-in effects, and pockets of market power. Internet telephony is an example, where firms, standard setting alliances, and political institutions create a hybrid market-based / negotiated standard setting environment. The paper explores the development of this hybrid networking environment. It posits propositions which are illustrated by means of case studies of the DVD and Internet telephony.

\footnotetext{
${ }^{1}$ We thank researchers at KPN Research (Jeroen de Muijnck and Menzo Wentink) and Ericsson (Hans Bisseling, Marion Kok and Lucas Klostermann) for their insightful discussions.

2 Faculty of Technology Management, Eindhoven University of Technology, P.O. Box 513, DG 1.10, 5600 MB Eindhoven, The Netherlands. Tel. 040-2473087; fax 040-2432983; e-mail: f.j.h.m.vercoulen@ tm.tue.nl.

${ }^{3}$ Faculty of Economics and Business Administration, University of Maastricht, P.O. Box 616, 6200 MD Maastricht, The Netherlands. Tel. +31 43-3883654; fax. +31 43-3258495; e-mail:

M.vanWegberg@MW.UniMaas.nl and home page: http://www.unimaas.nl/ mwegberg/index.htm.
} 


\section{Introduction}

In Information and Communication Technology (ICT) industries, standardization processes play a large role in business strategies. Standardization consists both of technological processes of developing and testing standards, as well as of economical, political or social processes, including the selection of a standard from competing alternatives. Most research focuses on the outcome of standard selection, that is, on which standard gets selected (or becomes dominant). There is a question antecedent to that, namely, which process decides about the outcome. The selection process of standards can consist of the market mechanism, but there are alternative selection mechanisms. Changes in technology and regulation have created a variety of selection mechanisms or modes. This has given firms in recent years the option of influencing the mode of standard selection. What is an appropriate business strategy with respect to the standard selection mode? Which factors should it take into account? This paper identifies various modes of standard selection, and it provides a framework for assessing a firm's preferred mode.

In the case of the market selection mode of standards, the product market decides about the evolution (dominance or obsolescence) of incompatible standards. A firm may develop a new standard and then introduce products in the market based on that standard. Other firms may do the same. Competition in the market place, a standards battle, decides which technology becomes dominant. The combination of competition instruments that firms have access to decides which firm and standard is most likely to win (see Van Wegberg, 1996, for an application to multimedia).

If firms want to avoid a standards battle in the market place, they will need to coordinate the development and introduction of the standard. They may form a forum or consortium for this purpose. If the industry features a regular flow of new standard proposals, there may be a permanent standard setting body. This is a negotiated standards selection mode. The government can impose coordination upon firms by means of an official standard setting body. Depending on regulation, firms must submit a standard proposal to this body, or they are free to do so.

Which standard selection mode exists, used to be industry-specific. Whereas standardization in the computer industry mainly evolved through the market place (Garud \& Kumaraswamy, 1993) or through voluntary standards organizations (David \& Greenstein, 1990) such as the ISO ${ }^{4}$, in telecommunications, standards were mostly defined or selected in official standards bodies, such as the $\mathrm{ITU}^{5}$, which is a formal treaty organization and run under the auspices of the United Nations (Cargill, 1989; Besen \& Saloner, 1989). Since networking has become more important and development of new technology faster and more costly, negotiated standardization through committees or alliances seems to become more important for the computer industry (Heywood et al., 1997). The telecom community tries

\footnotetext{
${ }^{4}$ International Organization for Standardization

${ }^{5}$ International Telecommunications Union
} 
to keep up with the speed of technological development by opening up the negotiation process to market players (David and Steinmueller, 1994; David \& Shurmer, 1996). The Internet, although grounded in the computer world, is a special case, as standards were completely open and established within the research communities of universities. Now that the Internet has become important to a much larger community of producers and users, other players are increasingly influencing its evolution. It is therefore interesting to try to find out if and how this development changes standards processes within the Internet community.

If there is no legal obligation that determines how standards are set, firms are free to choose the mode of standard selection. We examine their decision problem in the specific context of dynamic, complex industries, notably those in Information and Communication Technology (ICT). Our main contention is that pure forms of standard selection (market selection and negotiated selection) are giving way to hybrid market competition / negotiation selection modes in order to combine the benefits of both mechanisms.

We begin our analysis with an overview of the literature. This leads to a framework, which identifies factors that have an impact on the participants' preference for various selection modes. We illustrate this framework by case studies that demonstrate the trend towards hybrid standard selection processes.

\section{How Firms try to Cope with Complexity and Dynamics}

Recent developments in ICT have two dominating characteristics: complexity (of interdependent systems) and dynamics. These two trends used to be contradictory. A complex interdependent system tends to evolve very slow. In almost every country the railway system and the telecom network illustrate this inertia. Firms in ICT gradually developed an answer to these contradictory environmental demands. They split up their products into modules (separate units with a large degree of autonomy) (Langlois \& Robertson, 1992; Garud \& Kumaraswamy, 1995). Each module can be fairly simple, simple enough to allow for rapid change. The complexity results from coupling modules. There are joints between the modules that allow modules to interoperate to create a complex, interdependent, system. They have to interoperate to generate a value added for the user. If there are several alternative joints that can connect some modules, each module should be able to cope with these various possible joints with other modules. The advantage of simplicity would be lost. Hence, it is imperative to define standards for joints. The complex whole of standards that govern how a system and its modules interact, is called an architecture (Ferguson and Morris, 1994).

A system can now be dynamic even if it is highly complex. In a figure: 


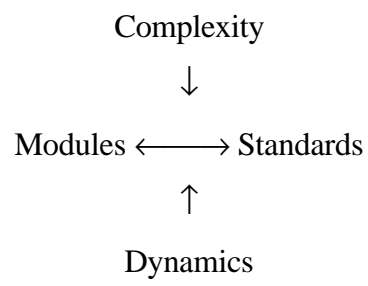

Standards are important because they solve the problem of how to combine complexity with dynamics. In order to survive in a complex / dynamic environment, business strategies create modular systems so as to be able to incorporate new developments in the firm's existing system. Firms try to design new technologies into modules that they can fit into their existing system architecture.

There are two kinds of fast dynamic processes in modular systems. One dynamic is called transmutational change (Garud, Jain, and Phelps, 1997) or modular innovation (Henderson and Clark, 1990). It consists of leaving the architecture roughly unchanged, while changing some modules (but not their joints to the rest of the system) very fast. By remaining loyal to the underlying architecture of a system, firms guarantee enough compatibility for customers and suppliers (subcontractors) to upgrade from one product generation to the next. Innovations and improvements are embodied in the modular components. These can be fitted into the system when needed, and can also be removed once obsolete. A rapid succession of small, incremental (modular) changes, can lead to an outcome that is radically new. This hybrid situation has similarities both with incremental innovations and with radical innovations. It combines compatibility between generations (path dependence; architectural inertia) with a fast succession of generations (path creation; modular innovations).

The opposite of transmutation is architectural innovation: the modules do not change (or not very much), but the architecture that connects them does (Henderson and Clark, 1990). The architectural innovation can be fast too, as the modules that it needs already exist. What is needed is new joints between these modules. New standards, and some new modules that embody these standards, are all it takes for an architectural innovation. The rapid spread of the Internet in the late 1990s with new services such as real-time video and telephony is an example. The Internet illustrates how important standards are to an architectural innovation: the key players in the Internet evolution are standard setting bodies such as the World Wide Web consortium and the IETF (Internet Engineering Task Force; see appendix 1 for abbreviations).

A proposition can summarize these ideas:

Proposition 1: The development of modular systems increases the dynamics (e.g., reduces the product life cycles) of complex industries.

\section{3. $\quad$ Standard selection mode in Complex / Dynamic Industries}


The architecture / modules approach has important implications for the mode of standard selection. Complexity (interdependence) and dynamics impose conflicting demands upon standard selection.

In complex, interdependent systems, all elements in the system need to fit tightly together. This offers little scope for the kind of experimentation that goes on in market selection of standards. Coordination is of paramount importance. Historically, in these industries the government tended to intervene to make sure that coordination would occur. Interdependent systems, such as a telephone network, also tend to require public access to the technology involved. Firms can submit their technology to a negotiated process, which means they can receive license fees if their technology is adopted, but only on conditions such as that they make the technology publicly available.

In dynamic markets, instead, negotiated standard selection takes too much time. Firms want to push forward their own technology. Rather than waiting for consensus to grow, or the governement to make up its mind, a firm will introduce its product in the market. This also gives it the opportunity to recover its investments in new technology. The advantage of self-controlled introduction of new technology is that it can try to impose conditions on the market that maximize its own gains from the technology. Under certain conditions, such as high entry barriers and market power, a go-it-alone strategy can offer high rewards to a succesful innovator.

The problem about modular systems is that they are both complex and dynamic. Hence, there are compelling reasons to combine the benefits of market selection (speed and appropriability) and negotiated selection (coordination and public access). We will now argue that firms do not simply choose between market selection and negotiated selection, taking the above mentioned (dis)advantages into consideration. Instead, they develop hybrid standard selection modes, that combine elements from competition and negotiation and that try to optimally reflect the weight of these factors. The table summarizes these conjectures.

\begin{tabular}{|l|l|l|l|}
\hline \multicolumn{2}{|l|}{ Standard selection mode } & Complexity \\
\cline { 3 - 4 } & Low & High \\
\hline \multirow{2}{|l|}{ Dynamics } & Low & (undetermined) & Negotiated selection \\
\cline { 2 - 4 } & High & Market selection & Hybrid selection mode \\
& & & \\
\hline
\end{tabular}

In words, we have

Proposition 2: In cases (industries) that combine complexity and dynamics, the standard selection mode tends to be a hybrid. 
Propositions 1 and 2 give the general framework to our analysis of standards selection. Figure 2 presents the key concepts and their relationships which we elaborate in the subsequent sections.

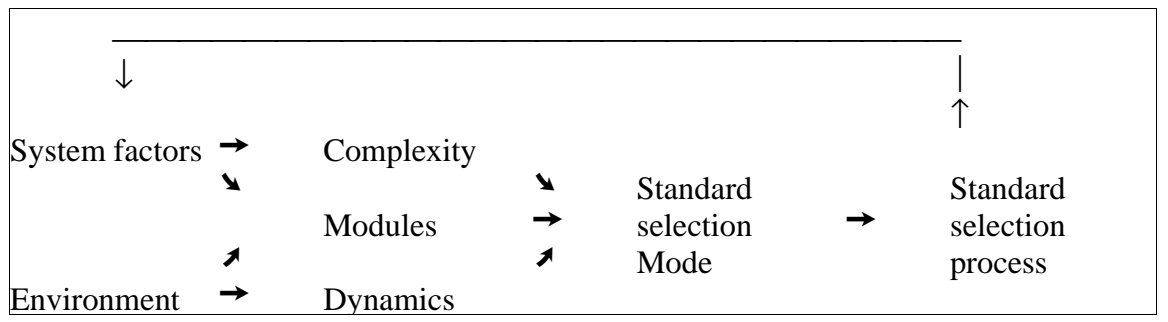

Figure 2 indicates that the combination of complexity and dynamics makes the development of modular systems imperative. But they also undercut attempts to select the standards required to make modular systems effective. Complexity and dynamics impose conflicting demands on the standard selection mode, e.g., the former calls for coordination and the latter for speed. Feedbacks abound in this approach. The outcome of a standard selection process, namely the existence and relative importance of standards, affects the systems and set of modules (or architecture), which in turn affects the standard selection mode.

\section{Factors that Affect the Mode of Standard Selection}

The core features of our framework consist of, respectively, modularity, dynamics, and complexity. We will discuss these determinants of the choice of standard selection mode one by one. In subsequent paragraphs we will look at the interaction of these determinants.

\subsection{Modular systems}

Modular systems are important because they make it possible to combine the two imperatives of modern business activity: complexity and dynamics. We have seen that modular systems depend very much on the existence of standards, but we also saw that there is no predominant model yet for selecting standards in a modular (complex/ dynamic) system. The latter problem may explain the slow and error prone progress towards modular systems. The complexity/ dynamic dialectic is both a driver of business strategies toward modular systems (to adopt innovations in an existing architecture) as well as an impediment (as it makes the choice of a standard selection mode more difficult). We focus our research on three general types of modular systems. We believe that they represent the dominant forms of modularity in ICT.

\subsubsection{Networks}


A network is a system of autonomous nodes with links between them. The units that make up the network are computers (in the case of a computer data communication network), people (in an organization), or organizations (in an alliance). Decision making is decentralized in that the nodes are able to take decisions within contraints: they are autonomous, but interdependent. The system is complex (think of the Internet, or a firm), but the units can be simple or limited (like individual people or personal computers). It can accommodate innovations by including new modules or nodes into the network.

There are increasing returns to adoption when the larger the network is, the more useful to its participants. Two quite distinct reasons exist for increasing returns to adoption (Matutes and Regibeau, 1996). Direct network advantages exist if users are primarily interested in interacting with each other. Examples are telecommunication and datacommunication networks. Indirect network advantages exist if users of a product care about its high quality or low cost products. These features in turn, may depend on the number of other users of the product due to economies of scale or scope.

An alternative for a network is a centralized system: for instance, a mainframe with terminals (see Tanenbaum, 1996, for the comparison). Centralization of decision making and information flows has benefits, but it requires a highly sophisticated centre (like the mainframe), which is costly, and may be very difficult to expand (inflexible).

These networks of technical instruments, people, and firms increase the need for interoperability standards and for coordination of the standards selection process. In addition, because networks increase interconnectedness, the scale of the technical systems that need to be managed rises considerably. Both consequences, interoperability and managability, tend to lead to the introduction of modules within the technical systems architecture between which precise interfaces are defined (Van den Dool, 1994).

\subsubsection{Hardware and software}

Modularity has been built into computers in various ways. The hardware and software can be decoupled from each other. For example, the Windows NT operating system operates on various microprocessors. The hardware is modular when there are various slots or connections to expand the PC by means of adding peripherals or chip-sets. PCI slots and USB connections offer leading examples of standard interfaces to expand the PC. An individual user's computer is thus a complex system, consisting of various modules, one of which is the PC itself.

Software is modular to some extent if there is a distinction between the operating system software and application software programs or between parts of such programs. Object Oriented (OO) programming is an example of an abstraction step through which a much higher degree of modularity in software can be achieved (Van den Dool, 1994; Garud \& Kumaraswamy, 1996). OO programming splits up a program in reusable, precisely defined objects. In this way, more complex programs can be built, 
which are in principle easier to manage with regard to performance and errors. In addition, cost savings are achieved, as objects are re-usable because of the precision with which interfaces are defined, and because coordination between objects and people working with these objects is facilitated. The Year 2000 problem is one of the many possible illustrations of the huge problems that can arise when modularity is not carried through far enough in software.

All this sounds like a very good idea. Still, a general standard for for OO has been slow in coming. One reason for this, apart from inertia of established players, is that OO requires an architecture for combining objects. The so-called object request brokers are building blocks for these architectures. Technically and strategically their importance is similar to operating systems. It will not come as a surprise that leading players in the field of computer software standardization, such as Microsoft, IBM, Apple, and Sun, all have or had their stakes. Currently, the contesting systems are DCOM, Distributed Component Object Model (Microsoft), Corba, Common Object Request Broker Architecture, (supported by Sun, Oracle, Netscape, IBM, and many others), and Java Beans (Sun, with considerable industry support). Early 1997, Apple and IBM terminated OpenDoc, which was their object request broker, and the alledged rival to Microsoft's DCOM (Automatisering Gids, 11-4-1997). The uncertainty about which of these architectures will dominate does little to speed up the transition to OO programming.

\subsubsection{Layering in telecommunication networks}

Modularity is built into contemporary communication networks by a layered architecture (see Tanenbaum, 1996). Each layer in the network provides a particular range of services to the the layer above or below via a precisely defined interface. As a result, each layer can in principle have its own product life cycle and its own degree of networking externalities.

The OSI ${ }^{6}$ layer model, developed by the ISO standards organization is one of the first examples of how such layering of an architecture is achieved. However, the OSI model also shows that such modelling attempts are not static, but are heavily dependent on environmental dynamics (see below). For example, due to liberalisation and technological developments such as the Internet, the OSI standards are seen as completely obsolete, whereas the underlying functional layer model is regarded as useful but also somewhat obsolete (Tanenbaum, 1996; Egyedi, 1996). This approach of breaking up a network system into parts, makes layering a form of modularity.

Modularity through layering can also be seen at a more general level from the point of view of the services provided (Smits \& De Vries, 1994). Such kind of layering has become more important as liberalisation and technological development have increased both the number of services that may be provided as well as the number of players that are dependent on each other. From a service (provider) point of view, a communications network has three layers that make up the transport of information: an infrastructure layer, a network layer, and a value-added service (VAS) layer. All these layers are made 
up of different kinds of technology, but must nevertheless interoperate in order to enable advanced and flexible service provision.

The infrastructure layer refers to the actual, physical network: cables, frequencies (for satellite and mobile communication e.g.) plus some technology to provide basic connectivity. Infrastructure has become unbundled to some extent, as many players build their own networks with so-called leased lines (many Internet (access) service providers, telephony resellers). These are lines hired from operators and they come in various forms. Some hire the actual line or frequency band and install and manage all the necessary technology themselves; others hire capacity managed by the operator to which they only add the technology needed to provide their service. The network layer performs the service of properly routing the information from one user to another (point-to-point), from various users to a single one (registration or consultation, depending on the direction of the main stream of information; multipointto-point) or broadcasting (point-to-multipoint). Finally, the third layer contains everything by which the basic network services are enhanced, so-called value-added network services (VAS). These are simple enhancements like voice mail, 0800 numbers and call centres, as well as more advanced services such as Intranets, Groupware and electronic commerce.

These examples suggest that in ICT, modular systems are increasingly important. A proposition summarizes the pros and cons of a modular system:

Proposition 3: The following are advantages (+) or disadvantages (-) of introducing a modular system:

- Specialization: different parties develop different modules (+)

- Diffusion: innovations can be adopted by including new modules in the architecture (+)

- Scale flexibility: the size of the system can be increased (decreased) by adding (removing) modules from the system $(+)$

- Coordination failures between modules (-)

- Resources devoted to linking and coordinating modules add overhead to the system (-)

- Creating an effective system by connecting modules (assembly) is a non-trivial task which requires expertise (-).

\subsection{Dynamics}

There are various developments in the market that affect the degree of perceived dynamics, which in turn affects both the need for a modular (re)design as well as the standard selection mode. We focus on environmental factors that the individual firm has little control over.

\subsubsection{The product life cycle}

\footnotetext{
${ }^{6}$ Open Systems Interconnection
} 
Products tend to stay in the market for a limited time, and this product life seems to have decreased in the past decades (D'Aveni, 1994). The technologies underlying these products are often more durable. In some industries, however, the lifetime of a technology too has been greatly reduced. The computer industry is an example (Brown \& Eisenhardt, 1997). The Internet contributes to shortening life cycles of software by offering a rapid distribution and diffusion network for new software programs. A negotiated settlement of a standard may now take too much time. Firms may want to be the first-mover with a technology. The outcome of several individual innovation efforts can be that these rivals introduce incompatible standards on the market. Rapid change favours market activity instead of coordinated selection of standards.

\subsubsection{Path dependence and the institutional context}

An important concept in standardization is path dependence (Arthur, 1989). Past developments and choices have a large influence on todays options. This holds for investments and technologies. It also holds for the networks of people who make the decisions about these technologies and who over time develop rules and routines for dealing with such complex processes. This may be more at the level of markets (Nelson \& Winter, 1982; Dosi, 1988; March, 1988) or at the organizational level (March \& Olsen, 1989; Scott, 1995; Tushman \& Romanelli, 1985; Langlois, 1986).

We already noted above that the Internet, the telecom and the computer industry created different institutional contexts for developing and selecting standards. The most obvious way to select a particular standard is likely to be the one that is supported by these traditional ways and institutions. Some developments may disrupt this inertia. Convergence between formerly separated industries, computers, telecoms and broadcasting, can be noticed, among others because of the still increasing importance of information exchange via communication networks. The convergence process seems to be part of an evolution towards communication networks that support a whole range of multimedia applications.

Thus convergence, innovations, and shortening product lifecycles induce a rethink of institutions and routines (Egyedi, 1994; David \& Shurmer, 1996). In the next sections, we show some institutional and strategic changes inspired by the need to accommodate the fundamental forces of network advantages and shortening product life cycles.

\subsubsection{Installed base of previous investments}

When users have already invested in a particular technology, they are unlikely to switch to an incompatible standard (Farrell \& Saloner, 1986; David \& Greenstein, 1990). If a firm anticipates this, it may prefer market selection of standards, in an effort to lock in customers to its proprietary standard. Customers, however, have become increasingly sophisticated. They realise that market selection is a 
game in which they run the risk of buying the wrong standard. Therefore, they become increasingly reluctant to participate in this game (Farrell \& Saloner, 1985). Their reluctance may stall the adoption of all incompatible standards submitted to the market. For instance, the incompatibility between Sony's MiniDisc and Philips' Digital Compact Cassette (DCC) led to consumers worldwide abstaining from buying either product. Market selection then selects out any new technology that is incompatible with existing standards. To overcome this hurdle, firms may have to negotiate among themselves a joint technology if they want to convince customers that their products are viable. This implicit bargaining power of customers increases if they already own substitutes to the new technology. In a mature environment, as ICT industries are slowly becoming, customers' preference for viable technologies seems to become an increasing factor in favour of negotiated standard selection.

\subsubsection{Vested interests, market structure and business strategy}

Due to network advantages, a standard is a natural monopoly: it is most efficient to have one standard to govern the joining of modules into a system. As a result, market selection of standards tends to pool most gains in the hands of the winners. A firm or alliance of firms will favour market selection of standards if it thinks it can win more by going alone than by negotiating with others. Several conditions determine the preference for market selection. Likely potential winners are the ones who have the best technical resources, market resources (market share dominance), architectural control, or a sizeable first move advantage in either the standard itself or in developing complementary products.

An organisation has architectural control if it determines whether a certain standard, technology, component or rule will be part of the architecture (Ferguson and Morris, 1994). Architectural control is valuable, because the firm that has it (the architectural organisation) sets the conditions and prices by which other companies can access its architecture. For example, makers of video games pay royalties to Nintendo for the right to release software for its machines. Once a firm has architectural control, it is unlikely to give it up for the sake of negotiated selection of standards.

Market share dominance tends to be important if standards are an instrument in competition (Katz and Shapiro, 1985). A monopolist or a dominant firm can use the market process to impose a standard upon any (potential) rivals. It is unlikely to participate in a negotiated settlement. Its very dominance assures that the advantages of a common standard are realised. In an oligopolistic market, multiple outcomes are possible. Firms may stick to their proprietary standards, forcing the market to select which one(s) to adopt. They may also want to coordinate, by means of one or more standard setting alliances.

If a firm owns technological resources, it is likely to defend that. It will sponsor any standards of its own. If it negotiates, it will want to defend its intellectual property rights. Case studies indicate that this may slow down negotiation processes. For example, an article on the G.729 speech standard reads: 
'At this point, AT\&T joined the optimization group. After solving some intellectual property issues, the group worked by correspondence on a very tight schedule.' (Schröder and Sherif, 1997)

The tedious process by which the GSM standard for mobile telephony came about and in which intellectual property rights played an important role is another example (Bekkers \& Liotard, 1998). This appropriability problem of firms' past investments in knowledge may be a factor in favour of market selection of standards.

Standard setting firms may accept negotiated selection rather than market-based selection if these winner-take-all conditions weaken: if their technological advantage, market power, architectural control, or first move advantages erode. These are four conditions, then, that determine whether marketbased or negotiated standard selection will occur.

To summarize the argument on the impact of dynamics on the mode of standard selection:

Proposition 4: Market selection tends to gain (+) or lose (-) importance if

- Product life cycles become shorter (+)

- Market selection is the traditional approach to standard selection (path dependence) $(+)$

- The technological leader, market leader, architectural organization or first mover prefers market selection to enhance its leadership (+)

- Customers are sophisticated and already own substitutes to new, incompatible, standards $(-)$.

- Intellectual Property Rights (IPR) are seen as important sources of income for a firm (+)

\subsection{Complexity}

Complexity is a third major factor influencing the mode of standard selection. There are many reasons why firms experience or perceive an increasing extent of complexity. The following three reasons are pertinent for ICT industries.

\subsubsection{Socialization of Standard Selection}

When a technology affects an increasing number of firms, customers, and others, these stakeholders in the standard will want to become involved in its development and selection process. In a market selection approach, firms introduce standards and customers choose among them. Subcontractors and governments have no say in the process at all. Customers can merely choose ex post, without being consulted ex ante. When a standard finally emerges, only those who supported it had a say in its development. Firms and individuals who supported other standards will have to adopt a standard they 
had no influence on. In a negotiated standard selection process, on the other hand, all affected by the standard have a say in its development and selection. The increasing importance of ICT standards to the (financial) bottom line of firms, and the increasing experience with standards, may increase the pressure on firms by their suppliers, customers, or other stakeholders, to offer products based on generally accepted standards and thus force them to accept a negotiated standard selection approach.

\subsection{2. (De)regulation}

The government may act as guardian of the public interest. It may act on behalf of the interests of large groups of stakeholders. It may therefore impose rules on the standardization process, or it may impose rules on the standards themselves. Deregulation creates uncertainty and requires firms to deal with a new range of possibilities and to adapt to new constraints. The government may also have an indirect impact. Antitrust policy or competition policy may restrain a dominant firm's market power, and it may forbid certain competitive tactics, such as dumping and predatory pricing (Stuurman, 1995). These change the competitive environment, and may change the incentives that firms have when choosing a standard selection mode (David \& Steinmueller, 1994).

\subsubsection{Globalization}

A globalization process may lead to coordination failures in public standard setting processes. A publicly negotiated standards battle can occur if the public process occurs within a limited geographic space. The European Union, for instance, ushered in the development of the GSM standard for mobile telephony. In the U.S., meanwhile, firms developed the CDMA standard. Both the U.S. and third countries are now a battleground between GSM and CDMA standards. This shows that a global market place calls for global standard setting bodies. Governments can use standards as an instrument in stimulating their own industry, or in imposing costs upon foreign industries. International companies may, on the other hand, have a wider perspective on the new standards, and may thus have a wholesome influence on the standard selection process. The rising influence of market forces on negotiated selection processes reflects both a change of industry policy objectives of governments and a shifting power balance between national governments and multinational firms operating in a global market place (Mansell, 1993; Hawkins et al., 1995).

A proposition summarizes the influence of these variables:

Proposition 5: The following factors tend to make the environment of standard selection more complex: 
- Increasing awareness among users and suppliers of the importance of external effects and standards, resulting in rising pressure on the standard selection mode

- Deregulation, re-regulation, and market liberalization, which increase the number and diversity of players

- Globalization, which widens the geographic scope of standard selection

- Convergence of markets (as in ICT) or of technologies (e.g., digital technologies).

\section{Choosing the Mode of Standard Selection}

To recap, firms face a range of standard selection modes in between the two extremes of market selection and negotiated selection. They also face a plethora of environmental factors that affect their choice: some of which operate to make their market more dynamic, or complex, or both. They also face systemic factors, over which they have some degree of control, such as the existing architecture(s), standards, and modular systems. Combining propositions 1 and 2 gives:

Proposition 6: Modular systems exhibit a trend towards hybrid standard selection modes.

The reason for this is that the existence of dynamics (indicated for instance by shortening product life cycles) tends to induce market selection. Complexity, which results for instance when direct network advantages exist, tends to call for coordination. Modularity combines both features. The following cases then suggest themselves:

\begin{tabular}{|l|l|l|l|}
\hline \multicolumn{2}{|l|}{ Choice of Standard Selection Mode } & Direct network advantages \\
\hline \multicolumn{2}{|l|}{} & Yes & No \\
\cline { 3 - 4 } & Short & Hybrid & Market \\
\hline Product life cycle & & & (Undetermined) \\
\cline { 2 - 4 } & Long & Negotiated & \\
\hline
\end{tabular}

The main example for the case with direct network advantages and long product life cycles is the telecommunication industry, where standards are indeed routinely negotiated. The designated standard setting organization is the ITU (International Telecommunications Union), where government officials of the member states used to negotiate on standard selection. The computer industry shows the case where there are few direct network advantages (at least prior to the networked computer era), and where product life cycles are brutishly short. The standard selection processes do indeed tend to be market- 
based (Cargill, 1989). We should emphasize at this point that other systemic and environmental factors (such as market structure and business strategy) can modify these hypotheses.

\section{Business strategies and hybrid standard selection modes}

These Propositions 1 to 6 provide the backdrop to business strategies concerning standard selection modes. This section reviews various business strategies that create or contribute to hybrid modes. These hybrid business strategies try to achieve one of two alternatives. Either they try to limit the scope of a central coordinating agency. Or they try to privatize this role by having market vendors take up a coordinating role.

\subsection{Limit the scope of coordinating activities: negotiation-based hybrid selection modes}

Firms may try to limit the role of a central coordinating agency, or they may pre-empt the development of such an agency, by somehow splitting up the standardization process. Coordination can then be limited to some aspects of this process. The standardization process can be split up along some dimensions if any of the following exist: ${ }^{7}$

- Systemic dimension: the technological system consists of separable components

- Process dimension: standard selection is a process in separable stages

- Functional dimension: division of labour among different tasks in standardization (including research, development, communication, coordination, and interoperability testing).

A standardization process is separable along a (combination of) dimension(s) if the actual process, including decision making and standard selection, can be split up in highly autonomous processes. The following sections show how firms develop hybrid strategies along any of these dimensions or a combination thereof.

\subsubsection{Selecting standards module for module}

Firms may try to reduce the need for coordination by splitting a system up in modules. In a modular system, firms can choose standard selection processes that differ from module to module, and between modules and architectures. They do not have to make an all out choice between market selection and negotiated selection. Instead, they can have both. The standard selection mode can be optimised for separate modules or architectures.

For example, in the PC industry the days of the 3,5" floppy are finally drawing to a close. Its storage capacity of 1,44 Megabyte is no longer adequate. The market will decide whether the Zip drive 
from Iomega or the LS-120 from Compaq/Imation will succeed it. This is quite separate from other standardisation processes in the PC industry.

\subsubsection{Vendor involvement in a negotiated selection mode}

In a setting with negotiated standard selection, firms may intervene in the process of standard selection. Their aim may be to speed up standardization or to try to increase the impact of their market power (David \& Greenstein, 1990). Standardization is a process in, roughly, four stages, with feedback effects.

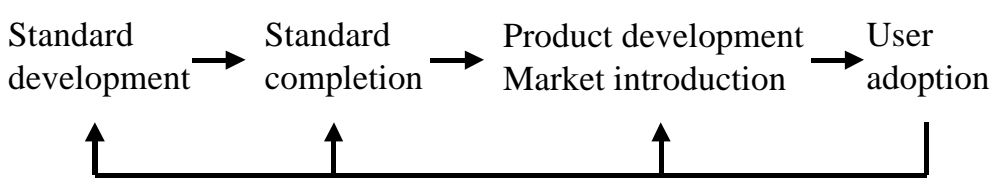

Figure 1: Four stages in a standardization process, with feedback effects

If the entire process is orchestrated by a central coordinating agency, say the ITU, it may exhibit the disadvantages discussed earlier. Vendors try to influence the process by appropriating a role in some of these stages. For example, firms may do most of the research in the standard development phase. A hybrid environment develops, where vendors launch proprietary standards, which at some point need to pass a standards body for wider acceptance. Vendors may act alone or in vendor consortia. An increasing number of rather influential vendor consortia have begun to intervene in the processes of official, regulating, standard setting bodies. They try do much of the real work, and may pass on their standard to an official standard setting body (Heywood et al., 1997). The latter, in a way, outsource standards development to focus on standard adoption (accepting and endorsing a technology as a standard).

The vendor involvement may speed up standardization, but at the possible loss of user involvement. By developing standards before an official body selects standards, firms can pre-empt the standardization process. Hence, vendors can bring their market power to bear both before selection

\footnotetext{
${ }^{7}$ We ignore a geographic dimension, as we focus on global ICT technologies and standards.
} 
occurs (by developing standards) and after (when they decide whether to implement the standard in products). To this effect, they split up the standardization process along the process and functional dimensions (mentioned above).

\subsubsection{Arm-twisting a Negotiated Standard Selection Process}

Without changing the structure of a negotiated selection mode, firms may try to change the outcome by the way in which they participate (Bailetti \& Callahan, 1995). In standard bodies which try to decide on the basis of arguments rather than market power, such as some Internet fora, firms dispatch increasing numbers of employees (Heywood et al., 1997). These employees participate in the public process much like anyone else, but they are likely to be beholden to their company's point of view. Companies may also attract employees who have a proven track record of influence in standard setting bodies. Indirectly, the size of the firm in the product market may translate into whose arguments are better understood.

\subsubsection{Premature product introduction and standard pre-emption}

Firms may try to jump-start a coordinated selection process by premature introduction of products. To the extent that their technologies are incompatible, this introduces an element of market selection into a coordinated selection mode (Farrell \& Saloner, 1988). Public or collective bodies are often slow to act. In the mean time, firms see business opportunities pass them by. Rather than waiting for the cows to come home, they may anticipate on a possible new standard. They will launch products that anticipate the new standard, but can be mutually incompatible. To avoid hurting consumers, suppliers may offer the possibility of later upgrading their product to the finally emerging standard (Katz \& Shapiro, 1985). The hardware of these pioneering products contains specifications the suppliers are sure will be adopted. Other parts are in software; customers can upgrade the software once the final specification has arrived. The initial incompatibility may also be strategic: it may represent an attempt to arm-twist the standard setting body into accepting some specification desirable to the firm involved. This is how the V.34 standard for $28.8 \mathrm{Kbps}$ modems and the V.90 standard for $56 \mathrm{Kbps}$ modems developed. The result is a negotiated standardization process with elements in it of traditional market selection. This hybrid strategy plays with the process dimension of standardization: some stages in this process (product development) can be started before the standard development and selection process is completed.

To sum up this section, a negotiated standard selection mode can develop into a hybrid mode if the standardization process is separable along a systemic, process, or functional dimension. If the separablity is absent, market forces cannot easily co-exist with a negotiated institutional process. In that case, a hybrid selection mode can evolve only if the market process itself can generate a negotiated, institutional, selection process. This is the topic of the next sub-section. 


\subsection{Private attempts at coordination: market-based hybrid selection modes}

Another class of hybrid standard selection strategies consists of vendors trying to realize a coordinating role. Market selection of standards sounds, as we said earlier, like competition, which favours diversity and speed at the possible cost of coordination. But the market process offers its own forms of coordination. We mention two: market leadership and cooperation by alliances or cartels.

\subsubsection{Market-based Hybrid Standard Selection Modes: Embrace and Extend}

We first consider a case where a market leader coordinates decisions of various rivals, suppliers, and other technology developers.

The traditional standards battle in the market is when firm 1 launches standard A and firm 2 launches the incompatible standard B, and the market decides which of the two will prevail. If compatibility becomes important (e.g., in networks), a standards battle becomes inefficient. Customers or suppliers who invested in the standard which ultimately looses, are left with useless investments. A new form of market selection emerges, that combines the good thing of market selection (speed and innovation) with the advantages from negotiation (coordination and compatibility), whithout negotiation itself. This is the hybrid strategy of 'embrace and extend'. If firm 1 launches standard A, firm 2 may license standard A, and then launch an improved version A+. It seems that firm 1 has won the standards battle. However, if most customers and suppliers accept A+, the control over the standard begins to shift from firm 1 to firm 2. Firm 2 can upgrade A+ over time into a standard B, which it owns (Mangematin \& Callon, 1995). Intel and Microsoft are masters in this strategy. Intel integrated mathematical coprocessors, RISC technology, and graphical operations (MMX) into its line of microprocessors. Microsoft integrated the graphical user interface from Xerox and Apple's Macintosh, icons from Lotus, Java from Sun, and numerous other ideas, into its Dos/Windows operating system. Gates' (1996, p. 273) own examples of embrace and extend are what Lotus did with Visicalc's invention of the spreadsheet, and Compaq with the IBM PC.

During this battle, incompatibilities can emerge. If one firm, such as Microsoft, wins, compatibility is restored. If a stalemate sets in, a family of related but slightly incompatible standards emerges. The Unix family of operating systems is an example.

Customers benefit from this strategy, as it means that all suppliers endorse a standard. It also means that a dominant firm can increase its dominance everytime someone makes an innovation. The dominant firm may do no more than integrate the innovation in its product line. The dominant firm, in a way, monopolises the coordinating role. The effect on users is a moot point. Merely integrating the innovation already pays off for customers: bundling reduces the hassle of integrating technologies oneself, the bundled package may be cheaper than buying products separately, and integration increases the complementarity between the existing technology and the innovation. 


\subsubsection{Market-based Hybrid Standard Selection Modes: Alliances}

If standards compete in the market, the parties that sponsor them may be alliances of firms, rather than individual players. This too is a hybrid form, comprising both market selection (if several standards hit the market) and negotiated selection (if an alliance hammers out a joint standard). Vendors have created standard setting bodies themselves, vendor consortia, such as the Gigabit Ethernet Alliance (GEA) and the ATM Forum. The alliance has more resources to launch the standard than any individual firm. It will have more technical resources to develop the specifications of the standard. It will also have more marketing clout to launch it. Moreover, by coordinating on a joint standard, the firms can avoid a standards battle among them.

We conclude from this section that there are two kinds of hybrid standard selection modes. The former consists of attempts to integrate elements of market selection in a negotiated or coordinated mode. The latter consists of including forms of coordination into the market selection mode (such as the development of a market leader). On the basis of the previous sections, we submit for further testing the following proposition:

Proposition 7: A negotiation-based hybrid mode will tend to dominate over a market-based hybrid if the following conditions hold:

- Coordination and direct network advantages are given more priority than shortening product life cycles;

- The standardization process is separable in one or more dimensions;

- There is no market leader (or a weak one).

\section{Cases of Standard Selection}

We now discuss two case studies about standard selection that illustrate business strategies in the interaction between systemic and environmental factors. Both cases are still under development, i.e. the outcome is not yet (fully) determined. They illustrate our argument that hybrid standard selection modes are a general feature of industries that are complex and dynamic, and where network economies play an important role.

The data from which the cases were constructed are taken from professional journals and a small number of interviews with technical experts from companies involved in standardization bodies. The DVD case was constructed from a longitudinal database consisting of articles of the Dutch IT and telecom newspaper Automatisering Gids. For the Internet Telephony case we used articles from Data Communications and IEEE journals, both well-known in the field of computer networking and telecom technical experts. We also conducted two interviews with experts on Internet Telephony 
standardization of KPN Research of Leidschendam, The Netherlands (2 people) and Ericsson Telecommunications of Rijen, The Netherlands ( 3 people) in order to test and further sharpen our framework.

\subsection{Case 1: the Digital Video Disk}

The Digital Video Disk (DVD) is physically the same product as the CD, at least in terms of size and outward appearance, but it offers more functionality, especially an increased storage capacity of digital data. Functionally, the DVD is expected to replace the CD, CD-ROM, and the video cassette tape. The technical system of the DVD consists of various components. It contains the physical format (the layers of material that make up the disk and the optical techniques to read the disk), a file format (UDF) for storing information on the disk, data formats (for audio, video, text, data), and copyright protection.

When it started, the standards battle about the DVD looked like a replay of the battle between the VHS, Betamax, and V-2000 systems for video cassette tapes and players. As it unfolded, it began to acquire some unique characteristics. The $\mathrm{CD}$ and the videocassette systems were introduced in market selection modes with some negotiation. In the case of the $\mathrm{CD}$, Philips and Sony teamed up to develop the technology, and then introduced the product in the market. Its resounding success forced other firms to accept this technology, and license it from the two pioneers. In the case of the videocassette, there were various rivals, each with support from friendly organizations. Since VHS acquired most support early on, both from the hardware industry and the movie industry, it gained a head start and installed base advantage that neither Sony with its Betamax nor Philips with its Video 2000 could overcome (Grindley, 1995).

Philips and Sony hoped for a replay of the CD success by developing the high density Multimedia CD with 3M (Automatisering Gids, 30-12-1994). However, Toshiba developed the Super Density disk (SD) in an alliance with Pioneer, Thomson, and Matsushita (Automatisering Gids, 3-21995). Toshiba managed to attract Time Warner into its camp. Time Warner being a media firm, they could not contribute to the technological work of developing the disk, but they did leverage their clout in the media industry. Now there were two competing camps. Both sides went looking for support. Mitsumi, Teac and Ricoh endorsed the High Density MMCD standard proposal from Philips/Sony (Automatisering Gids, 12-5-1995), as did Alps and Acer Peripherals (Automatisering Gids, 23-61995). The Super Density Digital Video Disc Alliance attracted support from Hitachi, JVC, Samsung, Mitsubishi, Thomson, and the media companies MGM/United Artists and MCA (Automatisering Gids, 23-6-1995). 
The initiative thus lay largely with the consumer electronics industry. ${ }^{8}$ The media industry became fragmented over the two camps. As in the case of the CD and videocassette, the media industry played a reactive role. It did however have a larger interest than choosing either side. A Hollywood Digital Advisory Group was formed, an ad-hoc group of large film producers that wanted to be involved in the standard setting process of the high density CD standards (Automatisering Gids, 23-6-1995). In particular, the American film industry wants the DVD to better protect against users copying films on DVD. The computer industry too had a joint interest. Apple, Compaq, HewlettPackard, IBM and Microsoft issued a joint statement calling for a single standard for high density CDs, both for entertainment and computer applications. They urged Toshiba and Philips/Sony to agree on a compromise that combines the best elements of both standards (Automatisering Gids, 23-6-1995).

The outcome of this was that the MMCD and SD alliances merged into the DVD Forum. By the end of 1995, all parties agreed that a single new standard had to be developed. It then took a long time to finalise the product, as the standards battle shifted from a battle in the market place to a battle of negotiation. American media companies, for instance, urged for better copyright protection by requesting eight incompatible versions of the disks and players, one for each region of the world (Automatisering Gids, 5-4-1996; Computable, 6-9-1996). The negotiations lead to a delayed introduction of the DVD. Not only do delays cause a loss of income, but they also open a window of opportunity for alternative technologies. The Divx company introduced a variety of the DVD system, Digital video express or Divx, which adds to DVD a payment scheme, but which does not support other features of DVD like subtitling (source: CNet, at http://www.cnet.com). The Divx re-introduces market competition about standards, which the DVD forum tried to prevent. This event suggests that a market-based hybrid selection mode may suffer from a lack of commitment by vendors to a negotiated outcome.

The traditional (routine) mode of standard selection for recording media is market selection. The development of network effects between media companies (whose costs increase if there are more recording media formats around), users (who benefit from low costs if the use of a particular medium like the CD or DVD is widespread), and manufacturers of (CD, DVD, cassette) players and disks or tapes, increased the costs of incompatibility and created a need for more coordination. The complexity of the technology increased as DVD is a multimedia format, unlike earlier technologies which either focused on music (cassette, DAT, CD), movies (videocassette, Laser Disc or Video-CD), or computer data (floppies, CD-ROM, ZIP drive). The DVD, that is, is technically more complex, due to convergence of various media types into multimedia. Its environment is also more complex as more parties are involved (recording companies, movie producers, and computer vendors) (see proposition 5). The media industry, for example, had learned that media standards, such as VHS and the CD, have a tremendous influence on their earnings potential. The combination of increasing complexity with the

\footnotetext{
${ }^{8}$ Toshiba is a bit of an outsider in consumer electronics. It is nowadays known as a computer firm, but it used to produce television sets.
} 
continuing dynamics of product innovation indicates the need for a hybrid standard selection mode (proposition 2).

The kind of hybrid that evolved is market-based rather than negotiation-based (see propositions 4 and 7). Vendors tried to build up market power as the coordination mode in establishing new standards. Media inventors such as Matsushita, Philips and Sony, tried to increase their market power over the media formats industry by acquiring media companies, such as music and movie companies. This approach clearly failed. In developing the Super Density disk, Toshiba, which has no market power in this area, stole a march over Philips and Sony by creating an alliance with a media company, Time Warner. Both Matsushita and Philips recognized this, when they decided to divest their media companies, MCA and Polygram, respectively. The alternative form of market coordination is the attempt to create an industry alliance. This, as we saw, was attempted by creating the DVD forum in late 1995 .

The difficulty of creating the institutional setting for a standard setting body such as the DVD forum, is that standardization in this area is difficult to separate in various stages, functions, or steps. Vendors cannot easily allow some coordination to be undertaken by a separate body, while continuing to develop their own technology and products. The DVD system is too tightly integrated for that. This makes a negotiated settlement difficult. The result is that standard selection is a hybrid, with a continuing role played by market selection and product incompatibility (proposition 7). Witness the Divx format as well as recordable DVD (DVD-RAM)

\section{Case 2: Internet telephony}

Whereas in the DVD case above only indirect network effects play a role - users do not need to communicate with each other - Internet telephony, and telephony in general, is a service which heavily depends on direct network advantages - communication between users is essential. Internet telephony is an alternative to traditional telephony in that the Internet instead of the traditional telephone network $\left(\mathrm{PSTN}^{9}\right)$ is used to transport speech from one user to the other and vice versa.

Figure 3 about here

There are several ways to realize Internet telephony (figere 3; Babbage et al., 1997). First it can be provided as a PC-to-PC service, so users involved in a conversation need a desktop computer with modem, microphone and soundcard. Second, it can be implemented as a telephone-to-PC, PC-to- 
telephone, or even telephone-to-telephone service, in which case a gateway between the Internet and the PSTN is required (Greenfeld, 1997). As a telephone-to-telephone service, the Internet serves as backbone, i.e. as the pipeline to transport speech from one telephone to the other. Finally, Internet telephony can be provided as a private service for companies over an Intranet - i.e. an internal Internet - thereby avoiding several of the management problems, such as congestion of traffic, occurring when providing it over a public Internet infrastructure.

However, originally, a datacom platform like the Internet was not intended to transport the real-time traffic that goes with telephony and videoconferencing services. The priorities in sending information differ between a datacommunication network, where avoiding data loss is the number one priority, and voice telecommunication, where avoiding delays is more important. Standardization is required to adapt the Internet network architecture to the demands of real-time traffic (proposition 7).

The company Vocaltec is credited with introducing Internet telephony commercially in 1995. Their product, Internet Phone, is a software-only product. Soon numerous rivals entered the market place, such as Quarterdeck, also a software company. Today, such applications are integrated as modules in software packages such as the Web browsers of Microsoft and Netscape.

These software products, however, only represent part of the architecture needed to provide Internet telephony as a service. The speech signals they code into digital format need to be transported via a network to another user who is able to decode the digital information again into speech signals. Also the network must be able to handle the coded information properly, so the products at the end points need to interoperate not only with each other, but also with the network that connects the two (or multiple) users. There are several reasons why this leads to a high level of complexity and dynamics in the industry (see propositions 4 and 5).

First, the products used at the end-points, where the users are, need to interoperate. Because there are many products available, either in hardware or in software, interoperability needs to be established in some way.

Second, multiple firms may be involved in providing the service, especially in the case of long-distance communication. Firms involved in providing Internet telephony are hardware and software producers providing the technology and telecom operators, Internet service providers, resellers etc. providing the service as a whole or parts of it, the latter e.g. in the case of international communication.

Third, Internet telephony is a perfect example of a case where the two formerly separated worlds of computers and telecoms come together. Therefore, there is a multitude of standards bodies, both official bodies and industry alliances, that have a stake in influencing the outcome of the standards process. Examples are the ITU and ETSI as official bodies for telecommunications, the IETF as the official standards body for the Internet, and the VoIP forum, part of IMTC, the ITC and

\footnotetext{
${ }^{9}$ Public Switched Telephone Network
} 
the VON consortium as industry alliances (see appendix 1). All these institutions have different histories and a different vision on how a service like Internet telephony should be implemented technically. Therefore, the multitude of organizations involved in the standards process again increases complexity.

The amount of products needed to put together an Internet telephony service, i.e. the number of modules, and the number of players involved in offering the service and producing standards for Internet telephony equipment has given rise to the H.323 architecture, developed by the ITU.

The umbrella standard H.323 comprises a multitude of standards modules, some of which already existed before, some of which have been newly developed, and some who are still under construction. The standard enables the end-user product to interoperate with the network, to set up connections with other users and terminate them, and to negotiate capabilities between end-users, e.g. 'do we have the same speech codecs or speech codecs that can at least interoperate with each other, so we are able to have a conversation?' and to use gateways between the tradional telephony network and the Internet. The underlying network (the Internet) is seen as a black box, which can thus have its own standard selection mode (paragraphg 6.1.1. and proposition 3).

H.323 is not a standard in the normal sense of the word: several speech codec are admitted, but not all products in the market support all speech codecs, so even if capabilities can be negotiated, a solution may not be found when trying to set up a conversation (proposition 3). This means that the standard selection mode is a hybrid one, because within the negotiated umbrella standard there is a de facto standards battle going on between the different variations in modules possible (propositions 2 and 6). Firms and standards bodies agree on certain codec standards (negotiated), but the market ultimately decides which one(s) is (are) going to be the standard(s) (proposition 5). An example is Microsoft's Internet telephony module NetMeeting, part of its Internet browser and developed through an alliance of Microsoft, Intel and Picturetel, which does not support all codecs, but only a few of them. As a result, the dominance of Microsoft in the browser market may also result in a de facto standard for parts of the H.323 umbrella standard.

It should also be noted that there are not only several standards bodies and alliances involved in formulating H.323, it has also a competitor within IETF, the major Internet standards body: SIP/SDP (Cordell et al., 1997). Interestingly, the same vendors that are negotiating H.323 in the ITU/ETSI, are also involved in formulating SIP/SDP. Whereas some of the literature focuses on the technical differences between the two standards (Cordell et al., 1997), our interviewees remarked that the historical differences between the two kinds of standards bodies also played a role - competences and division of labour between the study groups of different standards bodies, ITU, ETSI and IETF, were still under negotiation. This illustrates the possible important influence of path dependence on the standards selection mode (see also Egyedi, 1996; 1994) (proposition 4). 
Even more interesting is that firms are able to circumvent the possibly negative influence of the cultural battles over competence by participating in all the relevance standards bodies at once and postponing their definite choice until it is more clear what the best bet will be, both from a technical as well as a market perspective (proposition 6). There has even started work on integrating the best of the two in another standard, called SUCCESS (Cordell et al., 1997). The outcome of these competing processes is still unclear.

\section{Conclusion}

The two case studies in this paper indicate at the very least the need for a framework to understand and perhaps predict, how firms develop mechanisms (modes) for selecting standards. Competition is a game where the actual play constantly changes the rules of the game. Firms alternate between competition and cooperation. Moreover, their cooperation alternates between ad hoc efforts and institutionalized attempts to coordinate structural decision making. Systemic and environmental factors influence their strategies in this regard. We focused notably on modular design characteristics of systems, and two environmental features: complexity and dynamics. The interplay of these characteristics tends to determine how firms select a standard selection mode. Our cases show how negotiation emerges within market selection (the DVD case) and how market selection begins to take place in negotiated selection (IP telephony). Future research can test our propositions, and may enhance the analysis of the interaction effects between determinants and strategies, as well as between private and public players. 


\section{References}

Arthur, W.B. (1989) Competing Technologies, Increasing Returns, and Lock-in by Historical Events, The Economic Journal, 99: 116-131.

Babbage, R., Moffat, I., O'Neill, A. and S. Sivaraj (1997) Internet phone: Changing the telephony paradigm? BT Technology Journal, 15(2): 145-157.

Bailetti, A. J. and J.R. Callahan (1995), Managing consistency between product development and public standards evolution, Research Policy, 24: 913-931.

Bekkers, R. and I. Liotard (1998), European standards on mobile communications: the tense relation between standards and intellectual property rights, Internal research memo, Eindhoven University of Technology.

Besen, S.M. and G. Saloner (1989), The economics of telecommunications standards, in: Crandall, R.W. and K. Flamm (eds.), Changing the rules: Technological change, international competition, and regulation in communications, Washington, D.C.: The Brookings Institution, 177-220.

Brown, S.L. and K.M. Eisenhardt (1997), The art of continuous change: Linking complexity theory and time-paced evolution in relentlessly shifting organizations, Administrative Science Quarterly, 42: 134.

Cargill, C.F. (1989) Information Technology Standardization: Theory, process and organizations, Digital Press.

Cordell, P., Courtenay, M. and S. Rudkin (1997), Conferencing on the Internet, BT Technology Journal, 15(4): 51-63.

D'Aveni, R. (1994), Hypercompetition: Managing the dynamics of strategic maneuvering, The Free Press: New York.

David, P.A. (1985) Clio and the economics of QWERTY, American Economic Review, 75: 332-337.

David, P.A. and S. Greenstein (1990), The economics of compatibility standards: An introduction to recent research, Econ. Innov. New. Techn., 1: 3-41.

David, P.A. and M. Shurmer (1996), Formal standards-setting for global telecommunications and information services: Towards an institutional regime transformation?, Telecommunications Policy, 20(10): 789-815.

David, P.A. and W.E. Steinmueller (1994) Economics of compatibility standards and competition in telecommunication networks. Information Economics and Policy, 6: 217-241.

Dool, F. van den (1994), Telecommunication system architectures: Dealing with complexity, International Journal of Communication Systems, 7: 1-6.

Dosi, G. (1988), The nature of the innovative process, in: Dosi et al. (eds.), Technical change and economic theory, London: Pinter Publishers. 
Egyedi, T. (1996), Shaping standardization: A study of the standards process and standards policies in the field of telematic services, $\mathrm{PhD}$ dissertation, Delft University of Technology, Delft, The Netherlands.

Egyedi, T. (1994), Grey fora of standardization, a comparison of JTC1 and Internet, Consultancy report for KPN Research, Leidschendam, The Netherlands.

Farrell, J. and G. Saloner (1988), Coordination through committees and markets, RAND Journal of Economics, 19(2): 235-252.

Farrell, J. and G. Saloner (1986), Installed base and compatibility: Innovation, product preannouncements, and predation, American Economic Review, 76(5): 940-955.

Farrell, J. and G. Saloner (1985), Standardization, compatibility, and innovation, RAND Journal of Economics, 16(1): 70-83.

Ferguson, Ch. H. and Ch. R. Morris (1994) Computer Wars: the Fall of IBM and the Future of Global Technology, New York: Times Books.

Garud, R., S. Jain, and C. Phelps (1997) Transmutational Change: Path Dependance and Creation in the Web Browser Market, presented to the workshop Path Creation and Path Dependence, Aug. 1997.

Garud, R. and A. Kumaraswamy (1996), Technological designs for retention and reuse, Int. J. Technology Management, Special issue on unlearning and learning for technological innovation, 11(7/8): 883-891.

Garud, R. and A. Kumaraswamy (1995), Technological and organizational designs for realizing economies of substitution, Strategic Management Journal, 16: 93-109.

Garud, R. and A. Kumaraswamy (1993), Changing competitive dynamics in network industries: An exploration of Sun Microsystems' Open Systems strategy, Strategic Management Journal, 14: 351369.

Gates, B. (1996) The Road Ahead, London: Penguin Books.

Greenfield, D. (1997) IP Telephony Gateways: Long Distance with a Local Touch, Data Communications, June 1997: 97-106.

Grindley, P. (1995), Standards strategy and policy: Cases and stories, Oxford: Oxford University Press.

Hawkins, R., R. Mansell and J. Skea, eds., (1995) Standards, Innovation and Competitiveness: The Politics and Economics of Standards in Natural and Technical Environments, Aldershot: Edward Elgar.

Henderson, R.M. and K.B. Clark (1990), Architectural innovation: The reconfiguration of existing product technologies and the failure of established firms, Administrative Science Quarterly, 35: 930.

Heywood, P., M. Jander, E. Roberts, and S. Saunders (1997) Standards, The Inside Story: Do Vendors have too much Influence on the Way Industry Specs are Written and Ratified?, Data Communications, March 1997: 59-72. 
Katz, M. and C. Shapiro (1985) Network Externalities, Competition, and Compatibility, American Economic Review, 75(3), June 1985: 424-440.

Langlois, R.N. (ed.) (1986), Economics as a process: Essays in the New Institutional Economics, Cambridge: Cambridge University Press.

Langlois, R.N. \& P.L. Robertson (1992), Networks and innovation in a modular system: Lessons from the microcomputer and stereo component industries, Research Policy, 21: 297-313.

Mangematin, V. and M. Callon (1995), Technological competition, strategies of firms and the choice of the first users: the case of road guidance technologies, Research Policy, 24: 441-458.

Mansell, R. (1993) The new telecommunications: A political economy of network evolution, London: Sage Publications.

March, J.G. (1988), Decisions and Organizations, Cambridge, MA: Basil Blackwell.

March, J.G. \& J.P. Olsen (1989), Rediscovering institutions: The organizational basis of politics, New York: The Free Press.

Matutes, C. and P. Regibeau (1996) A Selective Review of the Economics of Standardization: Entry Deterrence, Technological Progress and International Competition, European Journal of Political Economy 12: 183-209.

Nelson, R.R. \& S.G. Winter (1982), An evolutionary theory of economic change, Cambridge, MA: Harvard University Press.

Schröder, G., and M.H. Sherif (1997) The Road to G.729: ITU 8-kb/s Speech Coding Algorithm with Wireline Quality, IEEE Communications Magazine, Sept.: 48-54.

Scott, W.R. (1995), Institutions and Organizations, London: Sage Publications.

Smits, J.M. and J. de Vries (1994), Het lagenmodel: Een toekomstvaste basis voor inrichting en regulering van de telecommunicatiemarkt, Informatie \& Informatiebeleid, 11(3): 48-55.

Stuurman, C. (1995), Technische normen en het recht, Ph.D. dissertation Free University of Amsterdam, Amsterdam, The Netherlands.

Tanenbaum, A.S. (1996), Computer Networks, $3^{\text {rd }}$ ed., London: Prentice-Hall.

Tushman, M.L. \& E. Romanelli (1985), Organizational evolution: A metamorphosis model of convergence and reorientation, Research in Organizational Behavior, 7: 171-222.

Wallace, J. (1997) Overdrive: Bill Gates and the Race to Control Cyberspace, New York: John Wiley \& Sons.

Wegberg, M. van (1996) Architectural Battles in the Multimedia Market, in: N.W. Jankowski and L. Hanssen, eds., The Contours of Multimedia: Recent Technological, Theoretical and Empirical Developments, Luton: John Libbey Media; Ch. 3: 32-46. 


\section{Appendix 1 Standardization institutes relevant for Internet Telephony}

In a hybrid or fully negotiated standard selection process, vendors participate somehow in a collective process. How they do that differs from one standard setting group to another.

Name Full name (Location of secretariat and Website)

ETSI European Telecommunications Standards Institute (Sophia Antipolis, France; http://www.etsi.org)

IETF Internet Engineering Task Force (Reston, VA, U.S.; http://www.ietf.org)

IMTC International Multimedia Teleconferencing Consortium (http://www.imtc.org/main.htm)

ITC Internet Telephony Consortium (Cambridge, MA, U.S.; http://itel.mit.edu)

ITU-T International Telecommunications Union (Geneva, Switzerland; http://www.itu.ch)

VON Voice on the Net (http://www.von.org)

Relevant IETF workgroups include:

AVT Audio/Video Transport (http://www.ietf.org/html.charters/avt-charter.html)

IPTEL IP Telephony (http://www.ietf.org/html.charters/iptel-charter.html)

MMUSIC Multiparty Multimedia Session Control

(http://www.ietf.org/html.charters/mmusic-charter.html)

Activity group from the IMTC:

VoIP Voice over IP Forum (http://www.imtc.org/i/activity/i_voip.htm)

Relevant ITU-T study groups include:

SG8 Characteristics of telematic systems http://www.itu.ch/itudoc/itu-t/com8.html

SG16 Multimedia services and system http://www.itu.ch/itudoc/itu-t/com16.html

The IMTC VoIP forum endorses H.323 and clarifies it to enhance the interoperability of vendors? products (e.g., see http://www.imtc.org/i/activity/i_voip.htm and documents referred to there). The members of the IMTC are vendors, e.g., 3Com, AT\&T, British Telecom, Compaq, Corel, Vocaltec, Voxware, etc.).

In the ITU-T, government officials take the decisions. Vendors can only participate in the communication process. The ITU-T accepts the IMTC in the communication process concerning standards for two study groups: 8 and 16 (and SG13 being considered).

The ETSI describes its members as follows:

'The European Telecommunications Standards Institute (ETSI) is a non-profit making organization whose mission is to determine and produce the telecommunications standards that will be used for decades to come. It is an open forum that unites 457 members from 33 countries, representing Administrations, network operators, manufacturers, service providers, and users. Any European organization proving an interest in promoting European telecommunications standards has the right to represent that interest in ETSI and thus to directly influence the standards making process.? (Source: http://www.etsi.org/aboutetsi/).'

The ETSI lists the IMTC and the ITU as organizations it cooperates with either formally or informally. 
Figure 3

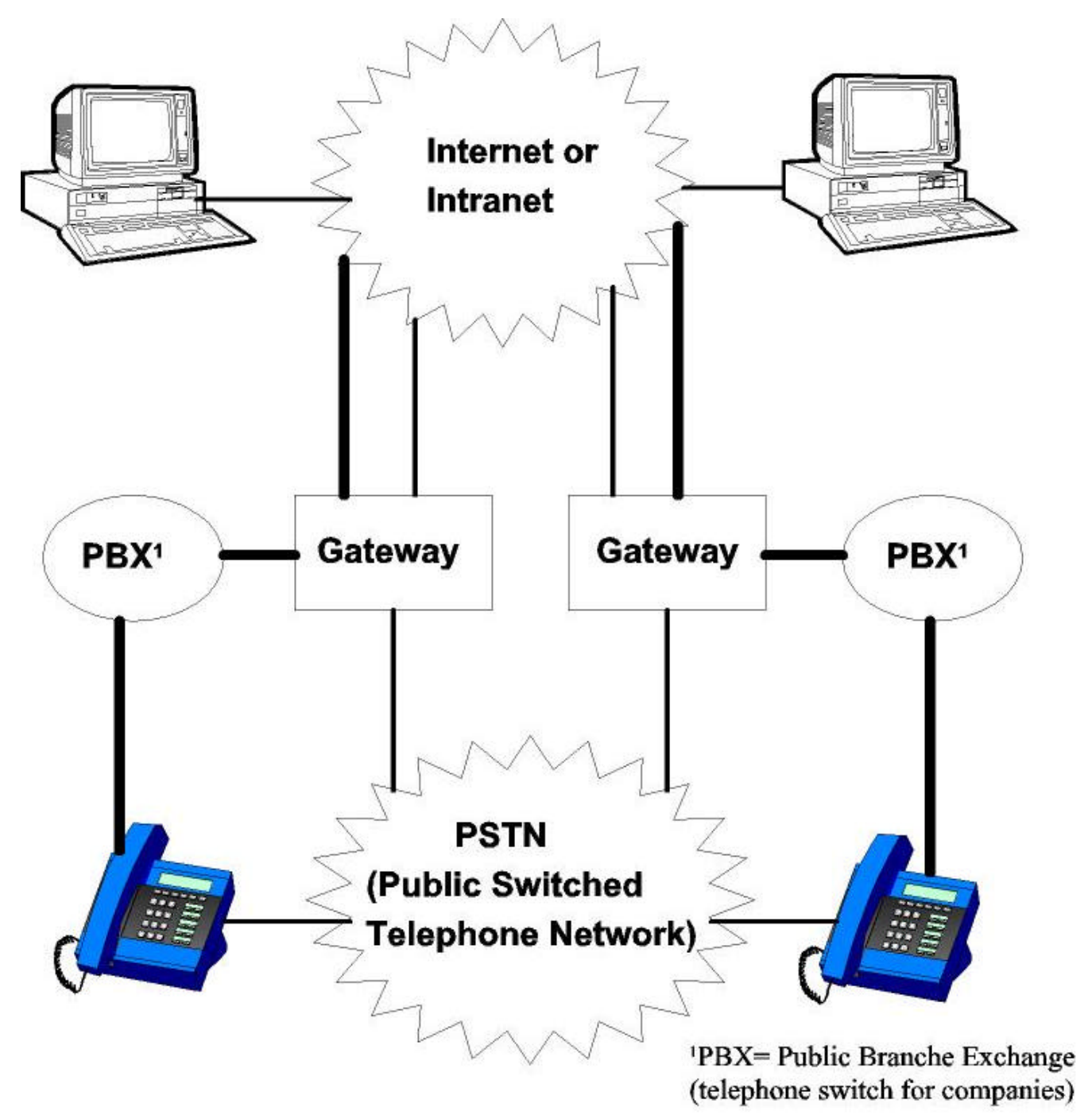

Figure 3. Possible ways to realize Internet telephony 